\title{
Oral Candidal carriage and associated risk indicators among adults in Sakaka, Saudi Arabia
}

\author{
Saad F. Alrayyes ${ }^{1}$, Hammad M. Alruwaili ${ }^{1}$, Ibrahim A. Taher ${ }^{1 *}$, Khaled M. Elrahawy ${ }^{2}$, Abdulrahman H. Almaeen ${ }^{1}$,
} Awad O. Ashekhi ${ }^{3}$ and Mohammad Khursheed Alam² (ID

\begin{abstract}
Background: Candida is a ubiquitous organism in nature which inhabits the oral cavity as part of the normal microbial flora. The oral carriage of Candida is perpetuated by several predisposing factors.

Methods: This cross-sectional study was designed to investigate the carriage rate of Candida among 104 voluntary adults at the college of medicine - Jouf University. The concentrated oral rinse technique using Sabouraud Dextrose agar medium supplemented with $0.05 \%$ Chloramphenicol was used to isolate Candida. The relative factors affecting the colonization of Candida and the concentration of each type were also determined.

Results: Candida species were isolated from the oral cavity of $45(43.4 \%)$ subjects. Of these $55.6 \%$ were identifies as C. albicans as determined by the Vitek 2 compact system. Other Candida species were represented by C. glabrata (11.1\%), C. krusei (11.1\%), C. dubliniensis (8.9\%), C. parapsilosis (6.7\%), C. tropicalis (4.4\%), and C. famata (2.2\%). Subjects with very poor plaque status, severe gingivitis and diabetes had significantly $(P=0.001)$ high concentration of Candida spp.
\end{abstract}

Conclusion: Plague, severe gingivitis, and diabetes were found to be significantly associated with higher Candida colonization.

Keywords: Candida spp, Mouth rinses, Oral hygiene, Risk indicators

\section{Background}

The term Candida originates from the Latin word "candid," which means white. Following the emergence of the Human Immunodeficiency Virus (HIV) and the widespread usage of immunosuppressive therapy, there has been a wide interest among scientists in these white fungi $[1,2]$. Of the over 200 known species of Candida only 40 are capable of causing disease. Candida albicans is the most prevalent isolated species in both symptomatic and asymptomatic candidiasis cases. In addition, $C$. parapsilosis, C. krusei, C. tropicalis, C. glabrata, C. dubliniensis, C. lusitaniae, and C. kefyr, which are collectively referred to as non-albicans, are increasingly involved in

\footnotetext{
* Correspondence: itaher@ju.edu.sa

${ }^{1}$ Department of Pathology, College of medicine-Jouf University, Aljouf, KSA, Saudi Arabia

Full list of author information is available at the end of the article
}

Candida cases and have been recognized as important pathogens [3, 4].

Candida are considered to be normal commensal organisms of the mouth that present most frequently in the posterior part of the dorsum of the tongue and can also be found on other body surfaces in the vagina and digestive tract $[5,6]$. However, Candida are known to elicit disease only if there is debilitation to an individual's immune status either locally or systemically [7]. In such cases, these commensals invade and penetrate the mucosal surfaces and form an essential step in the development of candidiasis [8]. Since candidiasis is often caused through endogenous infection by the Candida species, it is important to study and investigate the normal commensal flora of asymptomatic hosts at the population level.

The oral carriage rate of these organisms among the general population fluctuates between 3 and $75 \%$ without the appearance of any symptoms [9]. The disparity

(c) The Author(s). 2019 Open Access This article is distributed under the terms of the Creative Commons Attribution 4.0 International License (http://creativecommons.org/licenses/by/4.0/), which permits unrestricted use, distribution, and reproduction in any medium, provided you give appropriate credit to the original author(s) and the source, provide a link to the Creative Commons license, and indicate if changes were made. The Creative Commons Public Domain Dedication waiver (http://creativecommons.org/publicdomain/zero/1.0/) applies to the data made available in this article, unless otherwise stated. 
that has been noticed in the oral carriage rates of Candida might be influenced by multiple factors including demographic status, oral hygiene, and inconsistencies in the criteria of sample selection as well as in the analytical and sampling techniques used $[6,9,10]$. In addition, the carriage rates of oral Candida that have been reported to be more frequently associated with other factors are female gender, systemic diseases (e.g. diabetes mellitus), different blood groupings, tobacco smoking, and poor oral hygiene [11-14]. Additional factors such as geographical variations have also been suggested as affecting oral Candida carriage [9].

According to the information obtained from the indexed literature, data on asymptomatic oral Candida carriage in Saudi Arabia is limited to just one study [15] in which some aspects of oral Candida carriage and its relationship to poor oral hygiene were described in healthy Saudi subjects. Therefore, the objective of the present investigation was to study the carriage of Candida species (spp.) among adult individuals at Jouf University's Medical College, in Saudi Arabia.

\section{Methods}

This is a cross-sectional study that was carried out by performing clinical checkups, filling a questionnaire, and conducting a culture based microbiological investigation. Adult volunteers participated from both genders attending the college of medicine Jouf University. All candidates were given sufficient information about the study before being asked to formally consent to participate. The study protocol was also approved by the Medical Ethics Committee of the college of medicine, Jouf University. The population study was made of 104 adult individuals based on the calculation of a sample size measurement. The questionnaire contained questions on antibiotic/antifungal intake, and other health measurements and dental status.

\section{Collection of samples and identification of Candida isolates}

The concentrated oral rinse technique as described by Samaranayake et al. [16] for oral Candidal sampling was used in the present study. In brief, each participant was requested to rinse his/her mouth thoroughly for $60 \mathrm{~s}$ with $10 \mathrm{ml}$ sterile saline. The rinse was recollected into a sterile container, and was centrifuged for $15 \mathrm{~min}$ at 1700 g. The supernatant was discarded, and the pellet was dissolved into $1 \mathrm{ml}$ sterile saline. After thorough mixing for $30 \mathrm{~s}, 100 \mathrm{~mL}$ of each sample was transferred onto two agar plates of Sabouraud Dextrose medium (SDA, Oxoid - Basingstoke, U.K) supplemented with $0.05 \mu$ g chloramphenicol and incubated for $48-72 \mathrm{~h}$ at $35^{\circ} \mathrm{C}$ in air. All isolates that resembled Candida were gram stained and tested for Germ tube formation. Further identification of the yeast isolates was performed using the Vitek 2 compact 60 system (Biomerieux, France) according to the manufactures instructions.

\section{Oral assessment}

A visual examination using a probe and dental mirror was employed to perform the dental health status of the participants by the same researcher throughout the study. The dental health status and DMFT index (decayed, missing, and filled teeth) were assessed as described by Schuller and Holst [17]. The plaque thickness at the gingival area, and the plaque index (PI) were measured using the Silness and Loe method [18]. While, the gingival index (GI), and the gingival condition were evaluated using the Loe and Silness method [19].

\section{Self-reported data}

Information regarding age, gender, education or work status, oral health condition (history of dental caries), frequency of teeth brushing, and frequency of daily usage of mouth washes, smoking (current smoker, non-smoker) were all tabulated in a self-explanatory questionnaire. The body mass index (BMI, $\mathrm{kg} / \mathrm{m}^{2}$ ), blood grouping ( $\mathrm{ABO}, \mathrm{A}, \mathrm{B}$, and $\mathrm{O})$, presence of diabetes and hypertension were also recorded for all the participants.

\section{Statistical analysis}

The results were statistically analyzed using the Statistical Package of Social Sciences (SPSS) version 22.0. The Student's t-test or Mann-Whitney test (for non-normally distributed data) was used to compare the difference between the means; while the Chi-squared test was used to analyze the differences between frequencies in the different groups. The one-way ANOVA analysis was used to determine the correlation between the density of Candida and the plaque/gingival status. A value of $P<0.05$ was considered significant.

\section{Results}

Clinical characteristics and demographic status

Oral rinses were obtained from 104 adult subjects, of which 79 were males (76\%) and 25 were females (24\%). As shown in Table 1, the mean age of the study population was (25 years, $\mathrm{SD} \pm 10$ ). Blood group $\mathrm{O}$ was the most common $(44.2 \%$ among the study participants followed by groups A; AB and B). Only $12.5 \%$ of the study populations were smokers, $6.7 \%$ hypertensive and $5.8 \%$ were diabetics (Table 1 ).

\section{Carriage of Candida species}

Out of the 104 subjects examined, 45 (43.4\%) were found to be colonized with Candida spp. C. albicans was the most frequently encountered being isolated from 
Table 1 Characteristics of the study subjects and percentage (\%) carriage rate of Candida spp.

\begin{tabular}{|c|c|}
\hline & $\begin{array}{l}\text { (Total number }=104 \text { ) } \\
n(\%)\end{array}$ \\
\hline \multicolumn{2}{|c|}{ Presence of Candida } \\
\hline Yes & $45(43.4 \%)$ \\
\hline No & $59(56.7 \%)$ \\
\hline \multicolumn{2}{|l|}{ Candida spp. } \\
\hline C. albicans & $25(55.6 \%)$ \\
\hline C. glabrata & $5(11.1 \%)$ \\
\hline C. krusei & $5(11.1 \%)$ \\
\hline C. dubliniensis & 4 (8.9\%) \\
\hline C. parapsilosis & $3(6.7 \%)$ \\
\hline C. tropicalis & $2(4.4 \%)$ \\
\hline C. famata & $1(2.2 \%)$ \\
\hline \multicolumn{2}{|l|}{ Gender } \\
\hline Male & $79(76 \%)$ \\
\hline Female & $25(24 \%)$ \\
\hline \multicolumn{2}{|l|}{ Age groups } \\
\hline$<30$ & $90(86.5 \%)$ \\
\hline$\geq 30$ & $14(13.5 \%)$ \\
\hline \multicolumn{2}{|l|}{ Obesity (BMI $\geq 25$ ) } \\
\hline Yes & $48(46.2 \%)$ \\
\hline No & $56(53.8 \%)$ \\
\hline \multicolumn{2}{|l|}{ Co-morbidities } \\
\hline \multicolumn{2}{|l|}{ Diabetes mellitus } \\
\hline Yes & $6(5.8 \%)$ \\
\hline No & $98(94.2 \%)$ \\
\hline \multicolumn{2}{|l|}{ Hypertension } \\
\hline Yes & $7(6.7 \%)$ \\
\hline No & $97(93.3 \%)$ \\
\hline \multicolumn{2}{|l|}{ Smoking } \\
\hline Yes & $13(12.5 \%)$ \\
\hline No & 91 (87.5\%) \\
\hline \multicolumn{2}{|l|}{ Blood grouping } \\
\hline$A B$ & $17(16.3 \%)$ \\
\hline A & $26(25 \%)$ \\
\hline B & 15 (14.4\%) \\
\hline $\mathrm{O}$ & $46(44.2 \%)$ \\
\hline
\end{tabular}

23 (21.9\%) individuals and constituting (55.6.4\%) of the total isolates (Table 1). The mean concentration count (density) of the Candida was $505 \pm 1724$ CFU/ $\mathrm{ml}$. Other Candida species were also isolated though less frequently as C. glabrata and C. krusei both being found in 5 (11\%), 4 C. dubliniensis (8.9\%), $3 \mathrm{C}$. parapsilosis (6.7), 2 C. tropicalis (4.4\%), and 1 (2.2\%) C. famata.
Factors associated with colonization of Candida spp.

The oral Candidal carriage and concentration (density) among both males and females regardless of their ages (Table 3 ) was found to be not significantly different $(P=$ 0.35). Other factors such as, BMI (obese vs. non-obese), hypertension, and smoking all had no significant effect on either carriage rate or concentration of Candida among the study group. Although, the prevalence of oral carriage rate of Candida was comparable between diabetic participants and non-diabetic participants [4/45 (8.9\%) versus $41 / 45$ (91.1\%) respectively; $P=0.23$ ], nevertheless, the mean carriage concentration of Candida was significantly higher among diabetic participants than their non-diabetic counterparts [4492 (SD \pm 5629$)$ versus 293 (SD \pm 634$) \quad P \leq 0.00$; Table 3). Subjects with Blood group $\mathrm{O}$ were found to be associated with a higher frequency of oral Candidal carriage, while those with blood group A showed a higher amount (density) of Candida growth, however neither was significant (Table 2).

\section{Correlation between oral/dental hygiene and Candidal carriage}

As shown in Table 2, the oral carriage rate and concentration of Candida spp. among those who brushed or used mouth wash on a regular basis was comparable, but not significantly different. Similarly, dental caries though was associated with a higher rate of Candida carriage; however, it was not statistically significantly different from those reporting no dental caries. Additionally, no significant differences in the oral Candidal carriage $(P=0.85)$ among the subjects with the different plaque status was revealed. There were also no significant differences regarding the prevalence of oral Candida between subjects with no gingival inflammation, mild, moderate or severe gingival inflammation status $(P=0.11)$. Nevertheless, the mean concentration of Candida concentration was increased significantly as a result of poor gingival status, and likewise due to a poor plaque status $(P=0.01$, and $P=0.01$ respectively) as revealed by ANOVA analysis.

\section{Discussion}

Based on the very limited information regarding the oral carriage of Candida in our region [9] and to the knowledge obtained from the indexed literature, only one study has investigated the asymptomatic oral carriage of Candida [14]. Other studies have focused on Candida infections of the bloodstream, called Candidemia, or exclusively on diabetic groups or infants [19-21].

However, several studies [12-14] have shown wider variations of oral Candida carriage among healthy individuals. Also, Odds et al. [7] reported that the rate of Candida colonization found in the saliva or mouth washes of normal subjects ranges from 25 to $71.3 \%$. In a 
Table 2 Relationship between oral Candida colonization and oral hygiene status

\begin{tabular}{|c|c|c|c|c|}
\hline & Carriage of Candida $(n=45)$ & $p$-value & Mean CFU $( \pm S D)$ & $p$-value \\
\hline \multicolumn{5}{|l|}{ Daily teeth brushing } \\
\hline Irregular (intermittent) & $12(26.7 \%)$ & 0.70 & $538 \pm 202$ & 0.93 \\
\hline Once & $14(31.1 \%)$ & & $770 \pm 1786$ & \\
\hline Twice & $19(42.3 \%)$ & & $798 \pm 2905$ & \\
\hline \multicolumn{5}{|l|}{ Daily usage of mouth wash } \\
\hline Irregular (intermittent) & $24(53.3 \%)$ & 0.46 & $882 \pm 2630$ & 0.82 \\
\hline Once & $8(17.8 \%)$ & & $720 \pm 1008$ & \\
\hline Twice & $6(13.3 \%)$ & & $71 \pm 104$ & \\
\hline More than twice & $7(15.6 \%)$ & & $377 \pm 937$ & \\
\hline \multicolumn{5}{|l|}{ History of dental caries } \\
\hline Yes & $28(62.2 \%)$ & 0.19 & $823 \pm 2467$ & 0.16 \\
\hline No & $17(37.8)$ & & $409 \pm 763$ & \\
\hline \multicolumn{5}{|l|}{ Plaque Index (PI) ${ }^{\mathrm{a}}$} \\
\hline Very good & $10(22.2 \%)$ & 0.85 & $352 \pm 111$ & 0.01 \\
\hline Good & $24(53.3 \%)$ & & $563 \pm 293$ & \\
\hline Poor & $8(17.8 \%)$ & & $470 \pm 166$ & \\
\hline Very poor & $3(6.7 \%)$ & & $6480 \pm 3741$ & \\
\hline \multicolumn{5}{|l|}{ Gingival Index $(G \mid)^{b}$} \\
\hline No inflammation & $15(33.3 \%)$ & 0.11 & $129 \pm 240$ & 0.01 \\
\hline Mild inflammation & $23(51.1 \%)$ & & $586 \pm 1470$ & \\
\hline Moderate inflammation & $4(8.9 \%)$ & & $499 \pm 600$ & \\
\hline Severe inflammation & $3(6.7 \%)$ & & $4197 \pm 6480$ & \\
\hline \multicolumn{5}{|l|}{ Decayed, Missing, and Filled Index (DMFT) ${ }^{c}$} \\
\hline No Caries & $5(11.1 \%)$ & 0.09 & $230 \pm 337$ & 0.40 \\
\hline D-component (Decayed teeth) & $26(57.8 \%)$ & & $539 \pm 1386$ & \\
\hline M-component (Missed teeth due to caries) & $7(15.6 \%)$ & & $1841 \pm 4354$ & \\
\hline F-component (Filled teeth due to caries) & $7(15.6 \%)$ & & $277 \pm 430$ & \\
\hline
\end{tabular}

$\mathrm{a}=$ PI: Very good $<0.1$, Good $=0.1-0.9$, Poor $=1.0-1.9$, and Very poor $=2.0-3.0$

${ }^{\mathrm{b}}=\mathrm{Gl}$ : no inflammation $<0.1$, mild inflammation $=0.1-1.0$, moderate inflammation $=1.1-2.0$, and severe inflammation $=2.1-3$

${ }^{c}=$ DMFT: DT $>0$, MT $>0$ and FT $>0$

Data represent mean CFU/ml of colonizing Candida, $( \pm \mathrm{SD})$ and $P$-values

healthy Saudi Arabian population, Darwazeh et al. [14] reported a $52 \%$ prevalence rate for total Candida, of which $80.8 \%$ was $C$. albicans. These rates are comparable to our present findings ( $43.3 \%$ total Candida and $55.6 \%$ C. albicans) and consistent with the prevalence rate of 53\% reported by Patil et al. [22] among Indian adults. In addition, our results confirm that $C$. albicans is the most prevalent species in the oral cavity in comparison to other non-Candida albicans.

Some of the factors that were found to be associated with oral Candida colonization include age, gender, poor oral hygiene, smoking, and the presence of systemic diseases [2, 10-15, 22, 23]. Loster et al. [24] reported that oral Candida colonization was influenced by both age and gender; however, the subjects in this study were mainly denture-wearers.
A correlation between body mass indexes (BMI) and oral conditions has also been observed [25]. BMI was classified into the following three categories in the World Health Organization (WHO)'s World Health Report 1995: overweight (BMI $\geqq 25.1)$, acceptable weight (BMI > 18.5-25), and underweight (BMI $\leqq 18.4)$. We attempted to analyze the relationship between BMI and oral Candida carriage, but find no correlation. It was observed that smoking can affect Candida colonization [26] by indirectly influencing the level of salivary glucose, which in turn leads to increased Candida growth and colonization [26]. Nonetheless, our study did not demonstrate any clear link regarding this phenomenon, nor did it affect the status of the mean number of Candida colonization. Our results were found to be consistent with previous studies $[11,12]$ as 
they found that tobacco smoking on its own influenced neither the carriage rate of oral Candida nor the number of colonizing Candida.

Although several studies that have been conducted focus on the association between $\mathrm{A}, \mathrm{B}$, and $\mathrm{O}$ blood groups and Candida carriage [13, 27], contradictory observations have been reported, and other results lacked significant findings [28]. Therefore, the relationship between Candida species and $\mathrm{ABO}$ blood grouping remains inconclusive. Bamford-Mason et al. [13] showed that there is a significant relationship between the blood group $\mathrm{O}$ and Candida colonization, and our results were consistent with this, as we found that individuals with blood group $\mathrm{O}$ had higher carriage rates than those with other blood groups. Although Shin et al. [29] showed that most oral Candida carriers had blood group A, but there was no significant differences between the different blood groups.

The role of Candida species as a precursor of disease among diabetic patients was first described by Odds et al. [23], who observed a higher rate of oral candidiasis in patients with diabetes mellitus (DM) than in healthy individuals [30, 31]. However, another study has contradicted this relationship between DM and oral colonization by Candida [32]. Our results showed a significantly $(P=0.00)$ higher Candida count $(\mathrm{CFU} / \mathrm{ml})$ among diabetics than non-diabetics, as shown in Table 3. Although, these findings are consistent with some previous investigations [31-33], other studies did not show any significant differences between DM and the number of colonizing Candida [34].

Investigations into whether there is a relationship between hypertension and Candida colonization have also been conducted over the past 5 years [25]. Our study found that subjects who had mild hypertension had a prevalence rate of $71.4 \%$ for oral Candida carriage. There was also a higher mean number of colonies associated with the mild hypertensive subjects than their counterparts; however, neither of these findings was proven to be statistically significant. The relationship between hypertension and Candida colonization has yet to be clarified and might in fact be due to unhealthy lifestyles.

Several clinical investigations were performed to study the presence of a possible relationship between Candida colonization status and oral hygiene [12, 35]. In these studies, researchers observed an inversely relationship between better oral hygiene and reduced carriage rate of the number of colonizing cells of Candida spp. A recent study showed that a lower frequency of tooth-brushing was suggested to be associated with metabolic syndromes [36]. Other studies reported using mouth wash and aqueous extract of green tea led to reduction in the number of Candida cells [37]. On the contrary,
Table 3 Factors associated with Candida colonization

\begin{tabular}{|c|c|c|c|c|}
\hline & Candida carriage $(n=45)$ & $P$-value & Mean CFU $( \pm S D)$ & $P$-value \\
\hline \multicolumn{5}{|l|}{ Gender } \\
\hline Male & $34(75.5 \%)$ & 0.93 & $759 \pm 2247$ & 0.35 \\
\hline Female & $11(24.5 \%)$ & & $382 \pm 875$ & \\
\hline \multicolumn{5}{|l|}{ Age } \\
\hline$<30$ & $38(84.4 \%)$ & 0.59 & $760 \pm 2159$ & 0.21 \\
\hline$\geq 30$ & $7(15.6 \%)$ & & $157 \pm 343$ & \\
\hline \multicolumn{5}{|c|}{ Obesity (BMI $\geq 25$ ) } \\
\hline Yes & $20(44.4 \%)$ & 0.82 & $441 \pm 1416$ & 0.37 \\
\hline No & $25(55.6 \%)$ & & $847 \pm 2376$ & \\
\hline \multicolumn{5}{|c|}{ Co-morbidities } \\
\hline \multicolumn{5}{|c|}{ Diabetes mellitus } \\
\hline Yes & $4(8.9 \%)$ & 0.23 & $4492 \pm 5629$ & 0.00 \\
\hline No & $41(91.1 \%)$ & & $293 \pm 634$ & \\
\hline \multicolumn{5}{|c|}{ Hypertension } \\
\hline Yes & $5(11.1 \%)$ & 0.12 & $1609 \pm 2660$ & 0.20 \\
\hline No & $40(88.9 \%)$ & & $549 \pm 1909$ & \\
\hline \multicolumn{5}{|l|}{ Smoking } \\
\hline Yes & $6(13.3 \%)$ & 0.82 & $243 \pm 324$ & 0.20 \\
\hline No & 39 (86.7\%) & & $732 \pm 2138$ & \\
\hline \multicolumn{5}{|c|}{ Blood grouping } \\
\hline$A B$ & $8(17.8 \%)$ & 0.71 & $276 \pm 163$ & 0.21 \\
\hline$A$ & $13(28.9 \%)$ & & $1641 \pm 3504$ & \\
\hline B & $7(15.6 \%)$ & & $543 \pm 1080$ & \\
\hline 0 & $17(37.8 \%)$ & & $156 \pm 297$ & \\
\hline
\end{tabular}

Data represent mean $\mathrm{CFU} / \mathrm{ml}$ of colonizing Candida, $( \pm \mathrm{SD})$ and $P$-values

our prospective study couldn't demonstrate any association between frequencies of teeth brushing on a daily basis or the frequencies of usage of mouth wash on daily basis and Candida colonization.

In this study, we found no correlation between the plaque index status and the rate of Candida colonization. However, we found the concentration of Candida cells was significantly increased as a result of poor plaque index status $(P=0.001)$. We also couldn't demonstrate any significant differences between oral Candidal carriage and gingival status. On the other hand, a significant increase in the density of the number of Candida colonies among subjects diagnosed with severe gingivitis $(P=0.001)$ was observed. These findings are in agreement with previous studies that reported a significant relationship between the presence of oral candidiasis and gingival erythema in patients diagnosed with HIV infection [38]. Other studies have reported no significant relationship between Candida, plaque and gingival status [12]. We didn't found any significant correlation between caries history or poor DMFT scores and Candida colonization. Our findings regarding the 
increased density of Candida cells in subjects with very poor plaque status and/or severe gingivitis might substantiate other hypothesis which links Candida reluctance to preferably reside in subjects whose dental plaque is associated with poor oral hygiene, high level of plaque status, and presence of high level of gingival inflammation [38].

Limitation of study Using of self-reported data such as information on comorbidities (hypertension and diabetes) was based on recall basis.

\section{Conclusion}

Of all the studied indicators none seem to affect the rate of oral carriage of Candida among our subjects. However, very poor plague status, severe gingival inflammation, and diabetes were significantly associated with higher density of colonizing Candida spp.

\section{Abbreviations \\ BMl: Body mass index; CFU/ml: Colony Forming Units per milliliter; DM: Diabetes mellitus; DMFT: Decayed, missing, and filled teeth index; GI: Gingival index; HIV: Human Immunodeficiency Virus; PI: Plaque index; SD: Standard Deviation; SDA: Sabouraud Dextrose Agar.; SPP: Species}

\section{Acknowledgements}

We would like to thank Dr. Omar Dar, Family Medicine Department, Jouf University for helping with the statistical analysis of the data.

\section{Funding}

None.

\section{Availability of data and materials}

All the details are within the article in the results sections and as tables.

\section{Authors' contributions}

Conception and design of study/review/case series: SFA, HMA, AHA, AOA IAT, MKA. Acquisition of data: laboratory or clinical/literature search: SFA, HMA, KME, IAT. Analysis and interpretation of data collected: SFA, HMA, KME, IAT. Drafting of article and/or critical revision: SFA, HMA, KME, AHA, AOA, IAT, MKA. Final Approval: SFA, HMA, KME, AHA, AOA, IAT, MKA.

\section{Competing interests}

The authors declare that they have no competing interests.

\section{Publisher's Note}

Springer Nature remains neutral with regard to jurisdictional claims in published maps and institutional affiliations.

\section{Author details}

${ }^{1}$ Department of Pathology, College of medicine-Jouf University, Aljouf, KSA, Saudi Arabia. ${ }^{2}$ College of Dentistry, Jouf University, Aljouf, KSA, Saudi Arabia ${ }^{3}$ College of Dentistry, Ajman University, Ajman, UAE.

Received: 23 April 2018 Accepted: 29 April 2019

Published online: 22 May 2019

\section{References}

1. Egusa H, Soysa NS, Ellepola AN, Yatani H, Samaranayake LP. Oral candidosis in HIV-infected patients. Curr HIV Res. 2008;6:485-99 https://doi.org/10.2174/ 157016208786501445

2. Samaranayake LP. Oral mycosis in HIV infection. Oral Surg Oral Med Oral Pathol Oral Radiol Endod. 1992;73:171-80 https://doi.org/10.1016/00304220(92)90191-R.
3. Johnson EM. Rare and emerging Candida species. Curr Fungal Infect Rep. 2009:3:152-9 https://doi.org/10.1007/s12281-009-0020-z.

4. Arendorg TM, Walker DM. The prevalence and intra-oral distribution of Candida albicans in man. Arch Oral Biol. 1980;25:1-10 https://doi.org/10. 1016/0003-9969(80)90147-8

5. Pfaller MA, Diekema DJ. Epidemiology of invasive candidiasis: a persistent public health problem. Clin Microbiol Rev. 2007;20:133-63 https://doi.org/ 10.1128/CMR.00029-06

6. Cannon RD, Holmes AR, Mason AB, Monk BC. Oral Candida: clearance, colonization, or candidiasis? J Dent Res. 1995;74:1152-61 https://doi.org/10. $1177 / 00220345950740050301$.

7. Odds F C. Candida and candidosis. A review and bibliography. London: Baillier Tidall; 1988.

8. Kleinegger CL, Lockhart SR, Vargas K, Soll DR. Frequency, intensity, species, and strains of oral Candida vary as a function of host age. J Clin Microbiol. 1996;34:2246-54 https://doi.org/10.1128/JCM.40.2.341350.2002

9. Samaranayake LP. Commensal oral Candida in Asian cohorts. Int J Oral Sci. 2009:1:2-5 https://doi.org/10.4248/IJOS.08006.

10. Javed F, Klingspor L, Sundin U, Altamash M, Klinge B, Engstrom PE. Periodontal conditions, oral Candida albicans and salivary proteins in type 2 diabetic subjects with emphasis on gender. BMC Oral Health. 2009;9:12 https://doi.org/10.1186/1472-6831-9-12.

11. Oliver DE, Shillitoe EJ. Effects of smoking on the prevalence and intraoral distribution of Candida albicans. J Oral Pathol. 1984;13:265270 https://doi. org/10.1111/j.1600-0714.1984.tb01424.x

12. Darwazeh AG, Hammad M, Al-Jamaei A. The relationship between oral hygiene and oral colonization with Candida species in healthy adult subjects. Int J Dent Hyg. 2010;8:128-33 https://doi.org/10.1111/j.1601-5037. $2009.00407 x$

13. Bumford-Mason AP, Weber JC, Willoughby JM. Oral carriage of Candida albicans, $\mathrm{ABO}$ blood group and secretor status in healthy subjects. J Med Vet Mycol. 1988;26:49-56 https://doi.org/10.1080/ 02681218880000061

14. Al Mubarak S, Robert AA, Baskaradoss JK, Al-Zoman K, Al Sohail A, Alsuwayed $A$, et al. The prevalence of oral Candida infections in periodontitis patients with type 2 diabetes mellitus. J Infect Public Health. 2013:6:296-301 https://doi.org/10.1016/j.jiph.2012.12.007.

15. Darwazeh AM, Al-Dosari A, Al-bagieh NH. Oral Candida and nasal aspergillus flora in a group of Saudi dentate subjects. Int Dent J. 2002;52:273-7 https:// doi.org/10.1111/j.1875-595X.2002.tb00630.X.

16. Samaranayake LP, MacFarlane TW, Lamey PJ, Ferguson MM. Comparison of oral rinse and imprint sampling techniques for the detection of yeasts, coliforms and Staphylococcus aureus carriage in the oral cavity. J Oral Patho 1986. 15:563-5 https://doi.org/10.1111/j.1600-0714.1986.tb00646.x.

17. Schuller AA, Holst D. Oral status indicators DMFT and FS-T: reflections on index selection. Eur J Oral Sci. 2001;109:155-9 https://doi.org/10.1034/j.16000722.2001.00016.x

18. Silness J, Loe H. Periodontal disease in pregnancy. II. Correlation between oral hygiene and periodontal condition. Acta Odont Scand. 1964;22:121-35 https://doi.org/10.3109/00016356408993968.

19. Loe H, Silness J. Periodontal disease in pregnancy. I. Prevalence and severity. Acta Odont Scand. 1963;21:533-51 https://doi.org/10.3109/ 00016356309011240

20. Omrani AS, Makkawy EA, Baig K, Baredhwan AA, Almuthree SA, Elkhizzi NA, et al. Ten-year review of invasive Candida infections in a tertiary care center in Saudi Arabia. Saudi Med J. 2014;35:821-6.

21. Al Thaqafi AH, Farahat FM, Al Harbi MI, Al Amri AF, Perfect JR. Predictors and outcomes of Candida bloodstream infection: eight-year surveillance, western Saudi Arabia. Int J Infect Dis. 2014;21:5-9 https://doi.org/10.1016/j. ijid.2013.12.012

22. Patil S, Rao RS, Majumdar B, Anil S. Clinical appearance of Oral Candida infection and therapeutic strategies. Front Microbiol. 2015;6:1-8 https://doi. org/10.3389/fmicb.2015.01391.

23. Odds FC, Evans EG, Taylor MA, Wales JK. Prevalence of pathogenic yeasts and humoral antibodies to Candida in diabetic patients. J Clin Pathol. 1978;31:840-4 https://doi.org/10.1136/jcp.31.9.840.

24. Loster JE, Wieczorek A, Loster BW. Correlation between age and gender in Candida species infections of complete denture wearers: a retrospective analysis. Clin Interv Aging. 2016:11:1707-14 https://doi.org/10.2147/CIA S116658. 
25. Sato T, Kishi M, Suda M, Sakata K, Shimoda H, Miura H, et al. Prevalence of Candida albicans and non-albicans on the tongue dorsa of elderly people living in a post-disaster area: a cross-sectional survey. BMC Oral Health. 2017:17:1-10 https://doi.org/10.1186/s12903-017-0342-0.

26. Soysa NS, Samaranayake LP, Ellepola AN. Antimicrobials as a contributory factor in oral candidosis - a brief overview. Oral Dis. 2007;14:138-43 https:// doi.org/10.1111/j.1601-0825.2006.01357.x.

27. Bastiaan RJ, Reade RC. The prevalence of Candida albicans in the mouth of tobacco smokers with and without oral mucous membrane keratoses. Oral Surg Oral Med Oral Pathol. 1982;53:148-51.

28. Khozeimeh F, Mohammadpour M, Taghian M, Naemy V. A comparative study of Candida albicans means colony counts and blood group antigens in the saliva of healthy subjects. Dent Res J. 2014;11:240-3.

29. Shin ES, Chung SC, Kim YK, Lee SW, Kho HS. The relationship between oral Candida carriage and the secretor status of blood group antigens in saliva. Oral Surg Oral Med Oral Pathol Oral Radiol Endod. 2003;96:48-53 https:// doi.org/10.1067/moe.2003.S1079210403001604.

30. Khosravi AR, Yarahmadi S, Baiat M, Hi S, Pourkabireh M. Factors affecting the prevalence of yeasts in the oral cavity of patients with diabetes mellitus. J Med Mycol. 2008;18:83-8 https://doi.org/10.1016/j.mycmed.2008.04.002.

31. Kumar BV, Padshetty NS, Bai KY, Rao MS. Prevalence of Candida in the oral cavity of diabetic subjects. J Assoc Physicians India. 2005;53:599-602.

32. Bremenkamp RM, Caris AR, Jorge AO, Back-Brito GN, Mota AJ, Balducci I, et al. Prevalence and antifungal resistance profile of Candida spp. oral isolates from patients with type 1 and 2 diabetes mellitus. Arch Oral Biol. 2011;56: 549-55 https://doi.org/10.1016/j.archoralbio.2010.11.018.

33. Sashikumar R, Kannan R. Salivary glucose levels and oral candidal carriage in type II diabetics. Oral Surg Oral Med Pathol Oral Radiol Endod. 2010;109:706-11 https://doi.org/10.1016/j.tripleo.2009.12.042.

34. Safia A, Soliman O. Candidal colonization, strain diversity, and antifungal susceptibility among adult diabetic patients. Ann Saudi Med. 2010;30:101-8 https://doi.org/10.4103/0256-4947.60514.

35. Adachi M, Ishihara K, Abe S, Okuda K. Professional oral health care by dental hygienists reduced respiratory infections in elderly persons requiring nursing care. Int J Dent Hyg. 2007;5:69-74 https://doi.org/10.1111/j.16015037.2007.00233.x.

36. Pellizzaro D, Polyzois G, Machado AL, Giampaolo ET, Sanitá PV, Vergani CE. Effectiveness of mechanical brushing with different denture cleansing agents in reducing in vitro Candida albicans biofilm viability. Braz Dent J. 2012;23:547-54 https://doi.org/10.1590/S0103-64402012000500013.

37. Dehghani Nazhvani A, Haddadi P, Badiee P, Malekhoseini SA, Jafarian H. Antifungal effects of common mouthwashes on Candida strains colonized in the Oral cavities of liver transplant recipients in South Iran in 2014. Hepat Mon. 2016;16:e31245 https://doi.org/10.5812/hepatmon.31245.

38. Odden K, Schenck K, Koppang H, Hurlen B. Candidal infection of the gingiva in HIV-infected persons. J Oral Pathol Med. 1994;23:178-83 https://doi.org/ 10.1111/j.1600-0714.1994.tb01109.x

Ready to submit your research? Choose BMC and benefit from:

- fast, convenient online submission

- thorough peer review by experienced researchers in your field

- rapid publication on acceptance

- support for research data, including large and complex data types

- gold Open Access which fosters wider collaboration and increased citations

- maximum visibility for your research: over $100 \mathrm{M}$ website views per year

At $\mathrm{BMC}$, research is always in progress.

Learn more biomedcentral.com/submissions 